
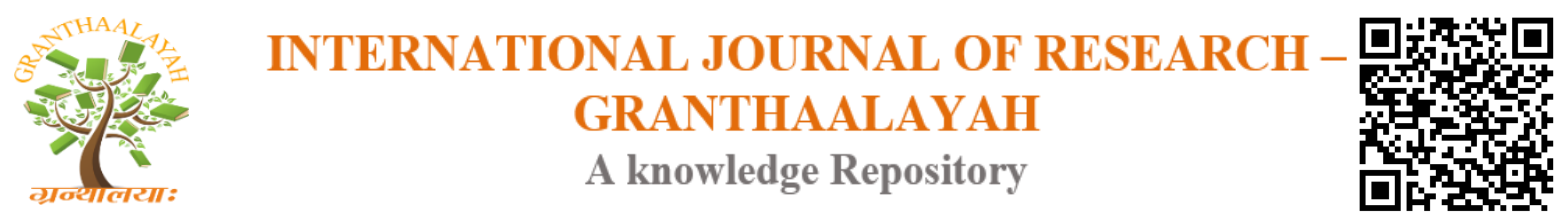

Science

\title{
ANALYTIC NETWORK PROCESS \& AXIOMATIC DESIGN: A STUDY IN FAST MOVING CONSUMER GOODS INDUSTRY
}

\author{
Atakan Alkan *1, Duygu Diyaroğlu ${ }^{2}$, Selen Avcı ${ }^{3}$, Zerrin Alada $\breve{g}{ }^{4}$ \\ *1, 2,3,4 Industrial Engineering Department, Kocaeli University, Turkey
}

\begin{abstract}
In this paper, customer criteria on selecting a baby diaper brand in the market of Egypt have been investigated and alternatives have been mentioned. In order to solve the problem Analytic Network Process and Weighted Axiomatic Design approaches have been suggested. On the first step of this study, via ANP method, market share forecast of different brands and priorities of criteria have been calculated, and those priorities have been used in Axiomatic Design Approach in order to view competitiveness of two brands which is on the top of market. Potential achievements of strategies based on strengthening weaknesses of brands, have been discoursed.
\end{abstract}

Keywords: Market Share Forecasting; Analytic Network Process; Weighted Axiomatic Design.

Cite This Article: Atakan Alkan, Duygu Diyaroğlu, Selen Avcı, and Zerrin Aladağ. (2018). "ANALYTIC NETWORK PROCESS \& AXIOMATIC DESIGN: A STUDY IN FAST MOVING CONSUMER GOODS INDUSTRY." International Journal of Research - Granthaalayah, 6(11), 7-22. https://doi.org/10.29121/granthaalayah.v6.i11.2018.1083.

\section{Introduction}

Today, in the environment of competition, companies have to use their resources efficiently while they are performing their activities in order to fulfill customer demands in a maximum level. Companies can only survive if they are covering the customer expectations.

Moreover, the main goal is having a profit and maximise it, and the only way of achieving this goal is having a big portion in market share. At the same time, they cannot ignore the importance of the critical factors such as quality, wide delivery network, innovativeness and cost.

In Fast Moving Consumer Goods (FMCG) industry, it is seen that the amount and the characteristic of criteria that customers are taking as a reference are varies day by day. As the consumption habits about products like baby diaper varies a lot from a market to another, companies need to consider the need of different specifications which will meet the demands of customers in the market that they are launching the product in. 
Also, protecting and increasing company's market share is really important especially in an environment which has a high level of competition and a customer demand that is being evolved according to innovations in the products. That's why, decision making is standing as the most critical function for top management. Main problem of decision making is choosing the best of the alternatives which is being evaluated by the criteria that are competing and getting up against each other [1].

In decision making problems, selecting the best choice will get more difficult in the situation of each alternative is having it's very own advantages. This is the reason why multi-criteria decision making models were being developed during in 1960.

The main purpose of using multi-criteria decision making models is to keep the mechanism of decisions making under control and achieving the results with an easier and quicker method [2].

Multi-criteria decision-making models are enabling decision makers to evaluate the given alternatives with multi criteria. Here the main purpose is to measure the fulfilling level of requirements of criteria by the given alternatives. Generally, via each method, decision maker calculates the scores of each alternative for each criteria and sort the alternatives according to their total scores. By this calculation the result will show him the generalized score of preference. Thus, the agreed solution in alternatives cluster is the one which has the highest score of preferences.

The first and the most important step of decision-making problems is to determine the number of unressive alternatives and criteria which is going to be used to evaluate those alternatives. Afterwards, data which indicates the preferences of decision makers needs to be collected. As a last step the best method for the specific problem needs to be applied in order to have the results. One of the widely used methods to evaluate the factors in a qualitative and quantitative way in order to make efficient decisions is Analytic Network Process (ANP) which has been discovered by Saaty [3]. Several studies using ANP method in recent years are as follows:

Aragonés-Beltrán et al. have presented a methodology to measure stakeholders' influences within a project in their paper [4]. The concept of influence is broken down into criteria, evaluating different aspects that together define an index which measures the influence of each stakeholder with respect to the rest of the project team. This index has been calculated with the Analytic Network Process. The methodology has been applied to a maintenance project for the Spanish National Railway Infrastructure company. As a result; have shown that the most effective stakeholders are the Contractor and the Signaling systems provider, which constitutes $40 \%$ of the total effectiveness.

Gur et al. [5] have examined the problem of choosing a marketing strategy for customers in the food industry to be advantageous to the market and to win customers. In the study, ANP and PROMETHEE methods are used integrally.

Asadabadi [6] have used a method to combine the analytical networking process (ANP), quality function distribution (QFD) and Markov chain to address supplier selection problem. This study introduces an innovative customer-based approach to select the best supplier that is independent of initial customer needs. 
In Ozcan et al.'s study [7]; hydroelectric, wind, biomass, solar and geothermal energy resources in Turkey have been ranking by TOPSIS method under 4 main criteria and 12 related sub-criteria comprised of technical, economic, social and environmental factors and the weights of criterias are calculated with ANP method.

Martino et al. [8] have focused on the particular field of the fashion retail industry in their paper. The particular case are referring to is represented by a fashion company that manages an extended network of wholesalers, direct operated stores, franchising mono-brand stores and factory outlet stores main aim of the presented work is to prioritise the list of identified risk factors by adopting the Analytic Network Process approach. The obtained results show that supply chain efficiency is considered the most crucial part also for a demand-driven supply chain as the fashion industry.

Wan et al. [9] have investigated supplier selection problem with two-level criteria and developed a novel hybrid method integrating TL-ANP (2-tuple linguistic analytic network process) and ITELECTRE II (interval 2-tuple Elimination and Choice Translating Reality II). TL-ANP approach, in which comparison matrices are consistent 2-tuple linguistic preference relations, is put forward to determine weights of criteria and sub-criteria. To deal with the case of criteria being not compensated, an IT-ELECTRE II approach is proposed. In this approach, ratings of alternatives on sub-criteria are represented as interval 2-tuple linguistic variables. As a result comparison analyses have conducted to illustrate the application and superiority of the proposed method.

Zhang [10] aims to contribute a theoretical framework and approach for the determination of top priorities in tourism development and making decisions based upon that approach in his study. Taking Xizang (Tibet) as a case, this study explores the means to weigh and realize tourism development goals during the '13th Five-Year Plan' period, using the analytic network process within a goal programming model. In addition, using the analytic network process-goal programming model, this paper provides the solution of the decision problem for two years, namely 2016 and 2020, and discusses the significance of the results.

Gok and Percin [11] have evaluated e-service quality of e-shopping sites with regard to e-servqual dimensions and order four e-shopping sites known by customers according to the performance of e-servqual with the proposed hybrid multi-criteria decision-making approach DEMATEL-ANPVIKOR. Within this scope DEMATEL method is used to make paired comparisons between criteria in company with expert team and then calculated weights is adapted to the Analytic Network Process (ANP). Afterwards, by the help of obtained data, e-shopping sites are ordered with VIKOR method.

Dincer et al. [12] have aimed to evaluate the balanced score card-based performance of Turkish banking sector with using ANP. They have made an analysis in order to determine which perspectives of balanced scorecard approach is appropriate for each type of banks (state banks, private banks, foreign banks).

Hussain et al. [13] have proposed an integrated framework based on interpretive structural modeling (ISM) and ANP to evaluate potential alternatives for sustainable supply chain management. The criteria used for evaluation are various enablers of sustainability, which are developed along economic, environmental, and social dimensions. The results of study 
demonstrate that governmental regulations, rewards and incentives, and listening to the views of the customers are the main enablers that can achieve sustainability in supply chains.

Ocampo and Seva [14] have examined a preference evaluation methodology for text entry methods in a touch keyboard smartphone using ANP. This study presents an alternative means for selecting text entry method that considers user preference. Results showed that QWERTY method is more preferred than other text entry methods while arrangement of keys is the most preferred criterion in characterizing a sound method.

Molinos-Senante et al. [15] have applied ANP for the selection of the most appropriate wastewater treatment (WWT) technology. Results illustrated that extensive technologies, constructed wetlands and pond systems are the most preferred alternatives by WWT experts.

On the other hand, there are many studies in the literature on the Axiomatic Design Approach, which has been developed bu Suh [16]. This method is providing us an opportunity to sort alternatives with their rating of fullfilling customer requirements. Several studies using Axiomatic Design method in recent years are as follows:

Arcidiacono et al. [17] have investigated the efficacy of lean management principles applied to the optimization of patient flows and related activities, structures, and resources, developing a theoretical framework based on the principles of the Axiomatic Design. In the framework, patients with similar characteristics are clustered in families to achieve homogeneous flows through the value stream. As a result, the Axiomatic Design-based top-down implementation of operation, according to lean principles, results in a holistic optimization of patient flows, by reducing the complexity of the system.

Güngör [18] have examined a problem related to the selection of seal material that needed by machine manufacturer with Axiomatic Design method. In this study, minimum limits of seal material required (design parameters-DP) have determined for working site. Then, possible seal materials were chosen from inside of research area between these limits created in material table. System intervals were determined according to the functional requirements (FR) of these materials. Among these, the selection of seal material that had smallest information axiom in total and that was suitable for probability distribution ranges was decided.

Babur et al. [19] have proposed a systematic approach for design of Lean-oriented Occupational Health and Safety (OHS) systems by using Axiomatic Design principles. A holistic roadmap is obtained as the output of the study for the application of OHS system to a production system. The proposed OHS system design have applied to a real-life shipyard system from shipbuilding industry and its feasibility have demonstrated.

Salonitis [20] have presented a framework to improve the current design approach for additive manufacturing using the axiomatic design approach. For the validation of the proposed framework, a bracket that traditionally is manufactured through milling of an aluminium alloy block have been selected as a case study. 
Zaralı and Yazgan [21] have discussed the location selection problem to position the logictics center using axiomatic design method. Alternative centers have been evaluated with certain criteria such as "land", "expansion field", "infrastructure possibilities", "closeness to the province".

Oliveira and A '1vares [22] have studied the application of Axiomatic Design to the development of a system for monitoring and teleoperation of a CNC machine through the internet. As a result, the functional requirements (FR) have been formulated and the design parameters (DP), which are represented by classes in an object-oriented application.

Liu and Li [23] have developed habit-forming products based on the Axiomatic Design Theory. An existing habit-forming product model, namely the Hook Model, have been reviewed with respect to its key components of trigger, action, reward, and investment. Essences of the Hook Model, together with its missing pieces, have been reformulated, repositioned, and resynthesized based on the Axiomatic Design Theory.

Arcidiacono et al. [24] have applied of Axiomatic Design for project-based learning methodology. The Axiomatic Design method have been applied to link learning outcomes of Lean Six Sigma training with all the teaching processes and the availability of resources. As a conclusion some improvement suggestions have been made to optimize the learning and teaching methodology in order to maximize the learner outcomes.

\section{Analytical Network Process (ANP)}

The Analytic Hierarchy Process (AHP) which developed by Thomas L. Saaty patterns decision making problems in a hierarchical and unidirectional way [25].

However, in ANP, hierarchy or feedback network is established and evaluations are made. Based on the control elements, the pairwise comparison and ratio scale are constituted. As a result, evaluation and scoring are synthesized within the network structure and the best alternative is selected [26]. In a network structure, there are three different components as shown in Figure 1. These components are classified as follows:

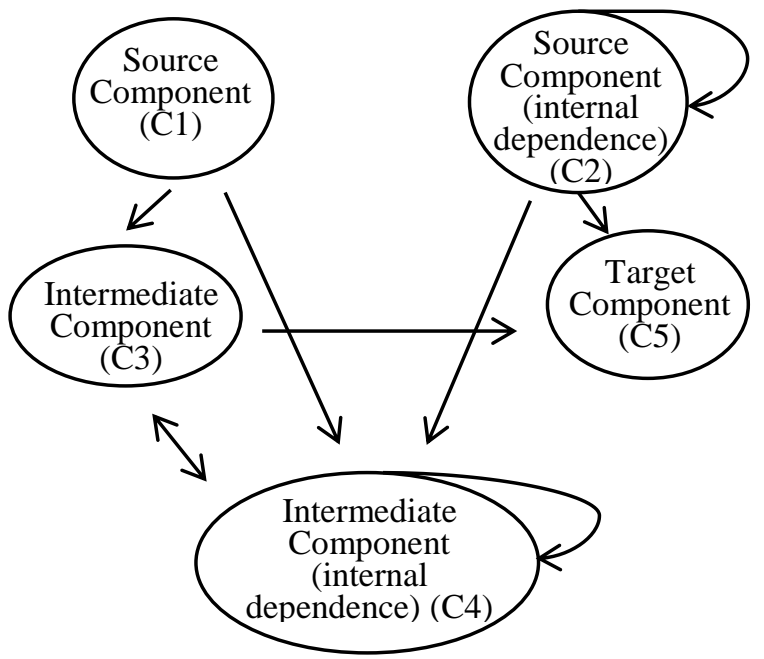

Figure 1: ANP Network Model 
The steps of the Analytic Network Process are as follows:

Establishing the model: First of all, decision making problem needs to be identified. Within this definition all alternatives, criteria and objective should be found. To build this network, it is necessary to reach a consensus with the decision-maker's working group, with brainstorming or other separation methods.

Determination of Interactions: The internal and external dependence between the criteria and the main criteria needs to be determined.

Pairwise Comparisons: Pairwise comparisons of criteria interacting with each other should be made. It is important to use a common scale when making comparisons. For this reason, the relative evaluation scale which has been specified by Saaty, shown in Table 1, is used.

Consistency analyzes of the pairwise comparisons are made. If the consistency results are lower than 0.1, the decision maker comparison's will be viable. If there is a comparison with a consistency ratio greater than 0.1 , the comparison should be reconsideration by decision makers.

Table 1: Relative Evaluation Scale

\begin{tabular}{|c|c|c|}
\hline $\begin{array}{l}\text { Intensity of } \\
\text { Importance }\end{array}$ & Definition & Explanation \\
\hline 1 & Equal importance & Two activities contribute equally to the objective \\
\hline 3 & $\begin{array}{l}\text { Weak importance of } \\
\text { one over another }\end{array}$ & $\begin{array}{l}\text { Experience and judgment slightly favor one activity } \\
\text { over another }\end{array}$ \\
\hline 5 & Essential or strong importance & $\begin{array}{l}\text { Experience and judgment strongly favor one activity } \\
\text { over another }\end{array}$ \\
\hline 7 & Demonstrated importance & $\begin{array}{l}\text { An activity is strongly favored and its dominance is } \\
\text { demonstrated in practice }\end{array}$ \\
\hline 9 & Absolute importance & $\begin{array}{l}\text { The evidence favoring one activity over another is of } \\
\text { the highest possible order of affirmation }\end{array}$ \\
\hline $2,4,6,8$ & $\begin{array}{l}\text { Intermediate values between } \\
\text { the two adjacent judgments }\end{array}$ & When compromise is needed \\
\hline
\end{tabular}

The vector of priorities consisting of pairwise comparisons is placed in the columns of the super matrix. The super matrix represents the priority of influence of the element in the left column of the matrix on the element in the top row of the matrix. The super matrix of a network is shown in Figure 2. 


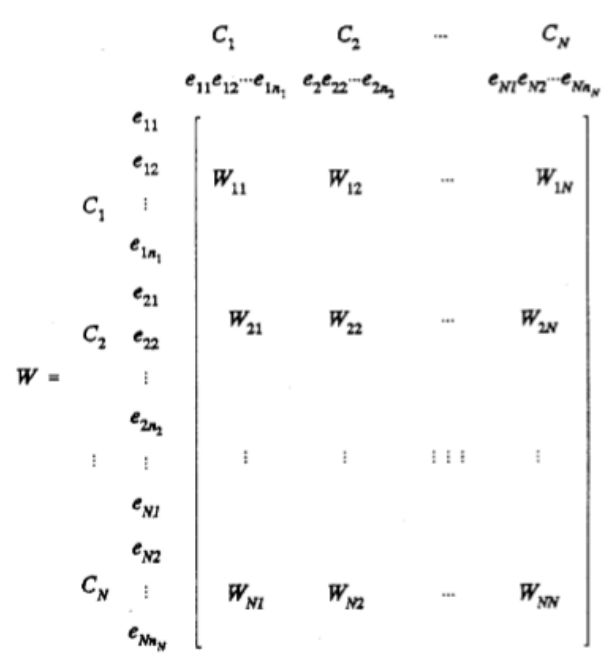

DOI: 10.5281/zenodo.1708230

Figure 2: Network Model Super Matrix Demonstration

To ensure that the weights of importance are equalized at one point, the $(2 k+1)$ power of the supermatrix, a segmented matrix, is taken. $\mathrm{k}$ is a randomly selected large number. The new matrix found is called the limit matrix and the limit matrix shows the importance weights of the factors and options of the problem [27].

\section{Axiomatic Design}

Axiomatic Design helps designing and understanding the design problems of designers and it enables the synthesis and analysis of appropriate design needs, solutions and processes. It is a design method introduced by Suh in 1990 [28]. Suh defines the Axiomatic Design with the interaction of "What do we want to accomplish?" and "How can we do it?" questions.

The main objective of this method is that the alternative to be selected the specified criteria have the optimum amount. It is also the main goals to make decision-makers more creative, to make the work done more efficiently, and to reduce the number of trial and error.

In today's competitive environment, especially as it this study in the fast-moving consumer goods sector, firms are under the pressure to make new product launches faster, reduce production costs, improve quality and reliability, and meet customer expectations in the best possible way. To reach this goal faster and with greater success, the knowledge and experience of the designers must be supported by scientific methods.

According to the Axiomatic Design approach, a good design is directed by two axioms.

Axiom-1 (Independence Axiom): Axiom 1 deals with the relationship between functional and physical variables. In an acceptable design, a design parameter (DP) may be arranged to provide the relevant functional need without affecting other functional requirements (FR).

Axiom-2 (Information Axiom): Axiom 2 deals with minimizing the information content. From alternative designs, the best design that provides the Independence Axiom has the minimum information content. 
Independence Axiom argues that the independence of functional needs $(\mathrm{FN})$, defined as the minimum number of independent functional needs that characterize design goals, must be sustained. When there are two or more functional needs, the design solution must provide each functional need without affecting other functional needs. This means choosing the right set of design parameters cluster that can provide their functional needs and maintain their independence [29].

Information axiom; argue that the best design is with minimal information content among the designs that provide the independence axiom because the information content is defined by the terms of probability. At the same time, the design with the highest probability of actualization according to the second axiom is the best design [29].

The information content (I) is defined by the probability of providing a given functional requirement (FR). If the probability of success of providing a given FR is $p$, then the information content I about the probability is expressed by the following equation (1).

$I_{\mathrm{I}}=\log _{2} \frac{1}{p_{i}}=-\log _{2} P_{i}$

Information is given in small units. At the same time, logarithmic function has been chosen to add information content when there are a lot of functional needs to be met. The total information content is the sum of all these possibilities if there are more than one FR. When sum of all probabilities are equal to 1 , the information content is zero. On the other hand, the required information is infinite when one or more possibilities are equal to zero. If this probability is low, it means that more information is needed to be met the functional needs [29].

The probability of actualization can be calculated by specifying the Design Range (DR) for the Fr and specifying the System Range for the design to provide the FR. As shown in Fig. 3, when the system probability distribution function of a FR is uniform, it is assumed that the intersection area of the 'design range' determined by the designer and the 'system range' realized by the system has acceptable solutions.

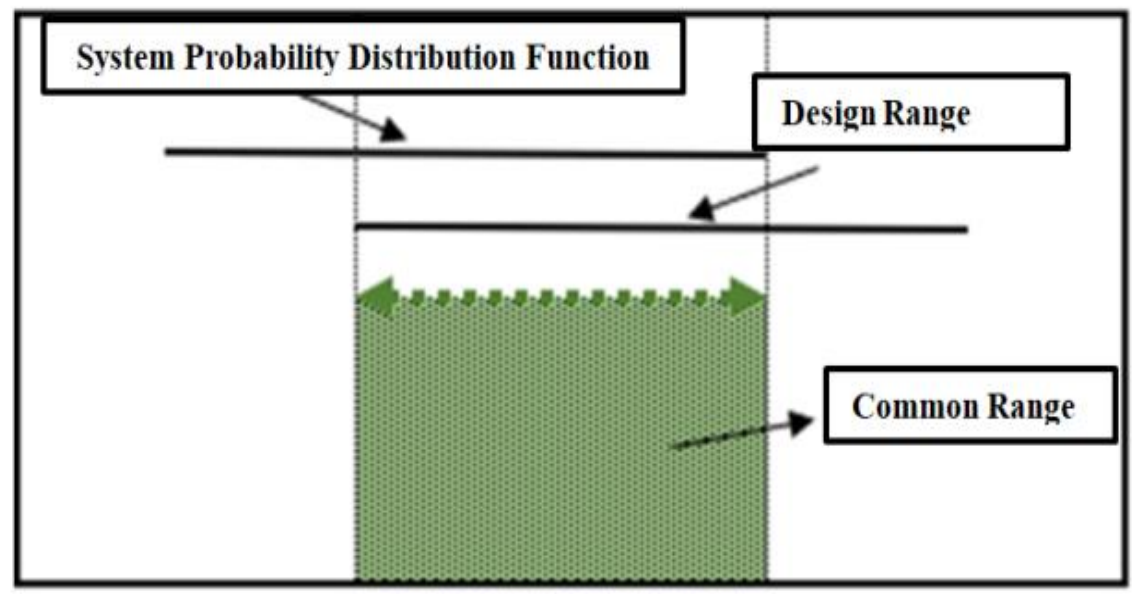

Figure 3: Design Range, System Range, Common Range and Probability Distribution Function 
In the case where the system probability distribution function is uniform, the probability of the actualization of FR is calculated by the common range/system range equation. From here, the equality of information content will be as follows (2).

$I_{i}=\log _{2}\left(\frac{\text { System Range }}{\text { Common Range }}\right)$

To the extent that information content is calculated so far, it is assumed that each criterion has equal weight. However, when each criterion has a different weight value (wj), the following set of equations must be used in addition to the existing formulations to calculate the weighted information content.

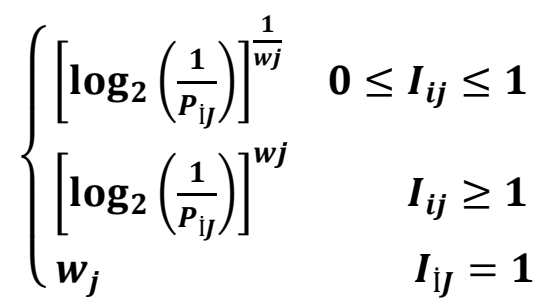

\section{Evaluating Customer Criteria for Baby Brand by Using ANP And Axiomatic Design}

In literature ANP and Axiomatic Design methods have usually been applied to the problems such as supplier selection and plant location selection. This study is to show the usage of integrated ANP and Axiomatic Design methods for market share and research \& development decisions.

In this paper, it is studied the baby diaper product in Egypt FMCG market. Model has 5 alternatives which has the biggest portion in related market. While creating the model criterias have been defined by marketing specialists via having a reference from market research studies.

Criteria's are as below:

Price: According to the several market study, price is the most important criteria for a customer while they are deciding on which brand to buy.

Promotion: Promotion ratio and frequency is coming after price criteria as one of the most important criterias.

Availability in the Market: In some markets having difficulties on finding the product because of geographical conditions and organizational abilities has a negative effect on customers. Products must be available anytime and anywhere in the market.

Absorbency: In order to provide a wakeless sleep and less need for changing diapers it's important to have high level of absorbency.

Leak-tightness: In direct proportion to the absorbency level, customers also requesting to have high level of leak-tightness on diapers. 
Skin Protection: Customers are aimed to change the diapers less frequently. That's why diapers must be skin protective.

Thinness: Moving freely is important for baby's development. And it's obvious that thin diapers are allowing babies to move more freely.

Strong Sticky Tapes: Diapers are for one time use only. When the tapes are not sticking well enough, there is a difficulty for mothers to use it and diapers get loose so mothers need to change it before it absorbs enough liquid.

Pleasant fragrance: For some customers it's important not to have odor before and after using the baby diaper.

Colored Product: Some customers says they are bored with White colored diapers and they would like to have cheerful drawing on the diaper.

After the criterias are defined, it is combined under 3 main clusters as Quality, Economy and Additional Features. Those clusters and networks between them have been created in Super decisions software.

Results of first running of the model by software it is noticed that the impact of the criteria Pleasant Fragrance, Colored Product, Thinness and Strong Sticky Tapes is less then $\% 3$ and decided to exclude them from model. After excluding those 4 criteria's the model has been run again.

Just after getting the model runs, comparison between actual and predicted market shares of selected brands is shown on Table 2 .

Table 2: Comparison of ANP model runs and actual market share (2017)

\begin{tabular}{|l|l|l|}
\hline Brand & Actual Market Share (2017) & ANP Predicted Market Share \\
\hline Brand A & $42,28 \%$ & $42,57 \%$ \\
\hline Brand B & $14,99 \%$ & $16,52 \%$ \\
\hline Brand C & $8,27 \%$ & $9,07 \%$ \\
\hline Brand D & $6,06 \%$ & $7,39 \%$ \\
\hline Brand Others & $28,40 \%$ & $24,46 \%$ \\
\hline
\end{tabular}

Priorities of all elements on decision are shown on Table 3.

Table 3: Priorities of criteria's

\begin{tabular}{|l|l|}
\hline Criteria & Priorties \\
\hline Price & $39,58 \%$ \\
\hline Promotion & $16,62 \%$ \\
\hline Availability in the Market & $10,47 \%$ \\
\hline Skin Protection & $3,35 \%$ \\
\hline Absorbency & $14,43 \%$ \\
\hline Leak-tightness & $15,55 \%$ \\
\hline
\end{tabular}


Till this step of study, market share of 4 top sold brand in Egypt has been calculated by ANP method. In the meantime, priorities of criterias, which is showing us the importance of each criteria on customer preferences have been calculated.

Next step is to show each Brand A and Band B's coverage levels on customer requirements related all important criterias.

On the first step of executing Axiomatic Design method, functional requirements of the model have been defined by marketing specialists in study group. Those requirements are listed on Table 4.

Table 4: Functional Requirements

\begin{tabular}{|l|l|}
\hline Criteria & Functional Requirements \\
\hline Price & $2,0-2,4 \mathrm{EGP} / \mathrm{Ped}$ \\
\hline Promotion & $7-9$ \\
\hline Availability in the Market & $8-9$ \\
\hline Skin Protection & $4-8$ \\
\hline Absorbency & $\geq 200 \mathrm{ml}$ \\
\hline Leak-tightness & $\geq 6$ hours (during night) \\
\hline
\end{tabular}

With same study group, design parameters for Brand A and Brans B are defined as below on Table 5 .

Table 5: Design parameters

\begin{tabular}{|l|l|l|}
\hline Criteria & $\begin{array}{c}\text { Design Parameters } \\
\text { (Brand A) }\end{array}$ & $\begin{array}{c}\text { Design Parameters } \\
\text { (Brand B) }\end{array}$ \\
\hline Price & $2,3-2,6$ & $2,3-2,6$ \\
\hline Promotion & $7-9$ & $6-8$ \\
\hline Availability in the Market & $8-9$ & $8-9$ \\
\hline Skin Protection & $7-9$ & $6-9$ \\
\hline Absorbency & $\leq 300 \mathrm{ml}$ & $\leq 280$ \\
\hline Leak-tightness & $\leq 12$ hours & $\leq 10$ hours \\
\hline
\end{tabular}

After it is defined functional requirements and design parameters, information contents of model have been calculated with related equation. Model runs are shown on Table 6.

Table 6: Information contents

\begin{tabular}{|l|l|l|}
\hline Criteria & Information Content (Brand A) & Information Content (Brand B) \\
\hline Price & 0,585 & 0,585 \\
\hline Promotion & - & 1 \\
\hline Availability in the Market & - & - \\
\hline Skin Protection & 1 & 2 \\
\hline Absorbency & 1,585 & 1,807 \\
\hline Leak-tightness & 1 & 1,322 \\
\hline \multicolumn{1}{|c|}{$\quad \boldsymbol{I}$} & 4,170 & 6,714 \\
\hline
\end{tabular}


On the last step which it is generated weighted information contents, it is used the priorities that have been calculated on the first step, ANP, of this study. Calculated information contants are shown on Table 7.

When it is analyzed the total information content raw $\left(\sum \mathrm{I}\right)$ on Table 7, Brand A has less value than Brand B with value of 1,516. Which means Brand A will be the first selection of customers according to Axiomatic Design Approach.

Table 7: Weighted information contents

\begin{tabular}{|l|l|l|l|}
\hline Criteria & Priorities & $\begin{array}{l}\text { Weighted Information } \\
\text { Content (Brand A) }\end{array}$ & $\begin{array}{l}\text { Weighted Information } \\
\text { Content (Brand B) }\end{array}$ \\
\hline Price & $40 \%$ & 0,258 & 0,258 \\
\hline Promotion & $17 \%$ & - & 0,166 \\
\hline Availability in the Market & $10 \%$ & - & - \\
\hline Skin Protection & $3 \%$ & 0,033 & 1,023 \\
\hline Absorbency & $14 \%$ & 1,069 & 1,089 \\
\hline Leak-tightness & $16 \%$ & 0,155 & 1,044 \\
\hline \multicolumn{1}{|c|}{$\sum \boldsymbol{I}$} & & 1,516 & 3,581 \\
\hline
\end{tabular}

However, as it's clear on same table, both alternatives have the same information contents for Price and Availability in the Market criteria. This is pointing the situation of equal opportunity for both brands. Therefore, those two criteria's have been eliminated from the model, priorities of left criteria's have been recalculated and weighted information contents are generated as shown on Table 8.

Table 8: Weighted information contents with recalculated priorities

\begin{tabular}{|l|l|l|l|}
\hline Criteria & Recalculated Priorities & $\begin{array}{l}\text { Weighted Information } \\
\text { Content (Brand A) }\end{array}$ & $\begin{array}{l}\text { Weighted Information } \\
\text { Content (Brand B) }\end{array}$ \\
\hline Promotion & $33 \%$ & - & 0,333 \\
\hline Skin Protection & $7 \%$ & 0,067 & 1,048 \\
\hline Absorbency & $29 \%$ & 1,142 & 1,187 \\
\hline Leak-tightness & $31 \%$ & 0,311 & 1,091 \\
\hline \multicolumn{1}{|c|}{$\sum \boldsymbol{I}$} & & 1,521 & 3,658 \\
\hline
\end{tabular}

\section{Conclusions}

It is known that beside marketing strategies, also level of income, education level, WOM (Word of mouth), culture and other demographic structure has a big impact on customer's buying behaviours. Thus, companies must analyze customer and market requirement really well before they are launching and build their marketing strategies accordingly. This is why some successful companies which are aware of how important analyzing the market is, are investing on market research activities. 
In this study a combination of ANP and Axiomatic Design methods is applied on a decision problem about baby diaper market. While creating the model, criteria and requirements are based on the selection of customers which are in C-socioeconomic group. As a beginning, model run with ANP method the outcome of the model has been compared with actual figures of related market.

After analyzing the model runs, Price criteria is coming with the highest priority for Csocioeconomic group. Following criteria with descending priorities, are Promotion with 16,62\%, Leak-tightness with 15,55\%, Absorbancy with 14,43\%, Availability in the Market with 10,47\% and Skin Protection with 3,35\% as shown on Figure 4.

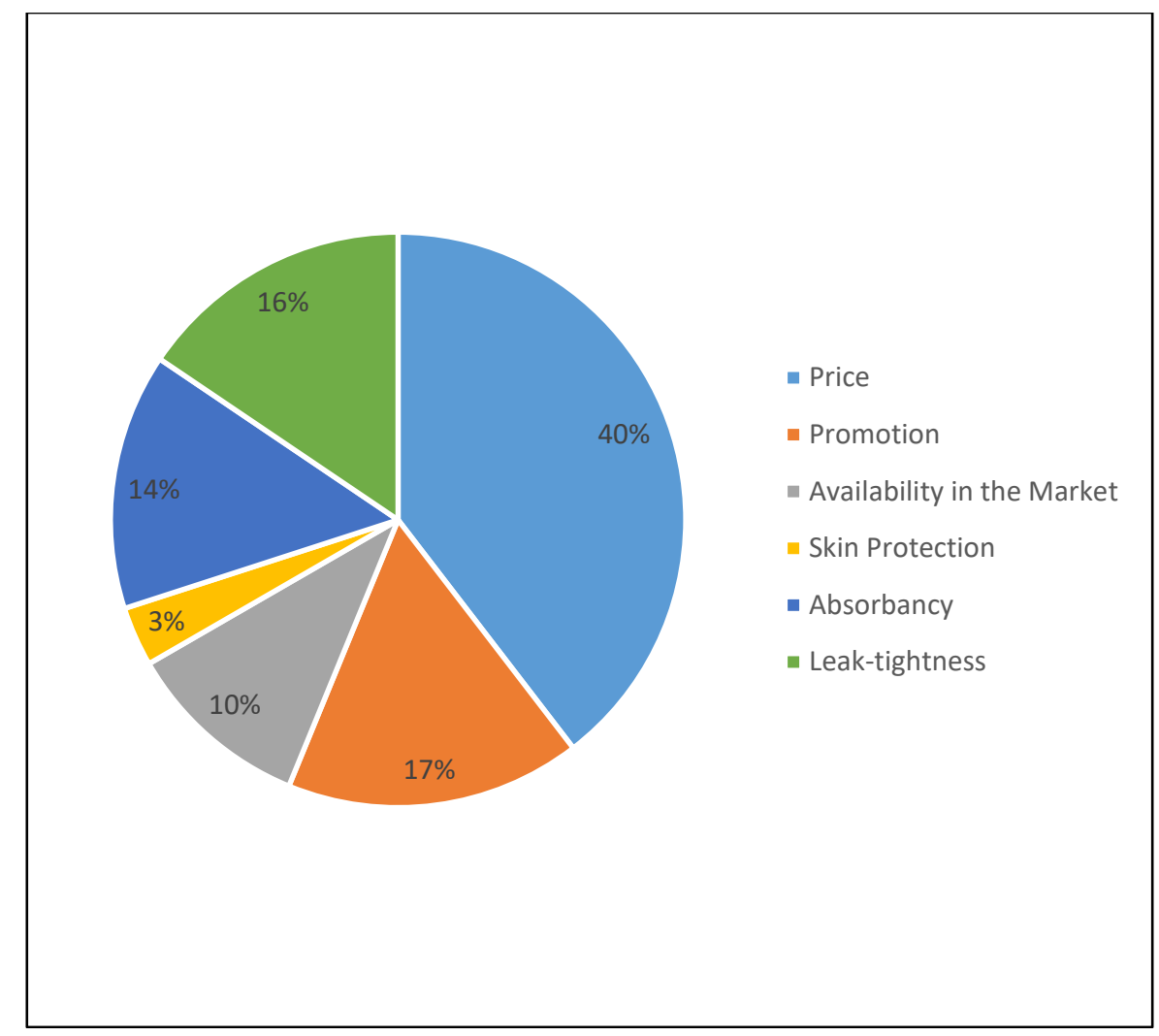

Figure 4: Priorities of criterias

According to the priorities come out from the model run with ANP, Price is coming as the most important point for product development and new product launching for companies in the market. While launching a new product, price must meet the customer expectations. In the meantime, research and development studies must be focused on Leak-tightness and Absorbancy features.

When it comes to analyze information contents, the outcomes of Axiomatic Design Approach, it is seen that Brand $\mathrm{B}$, which is actually having the second biggest portion in the market, needs to focus on developing it's product on specific features. Those are the ones with higher information contects on Figure 5. 


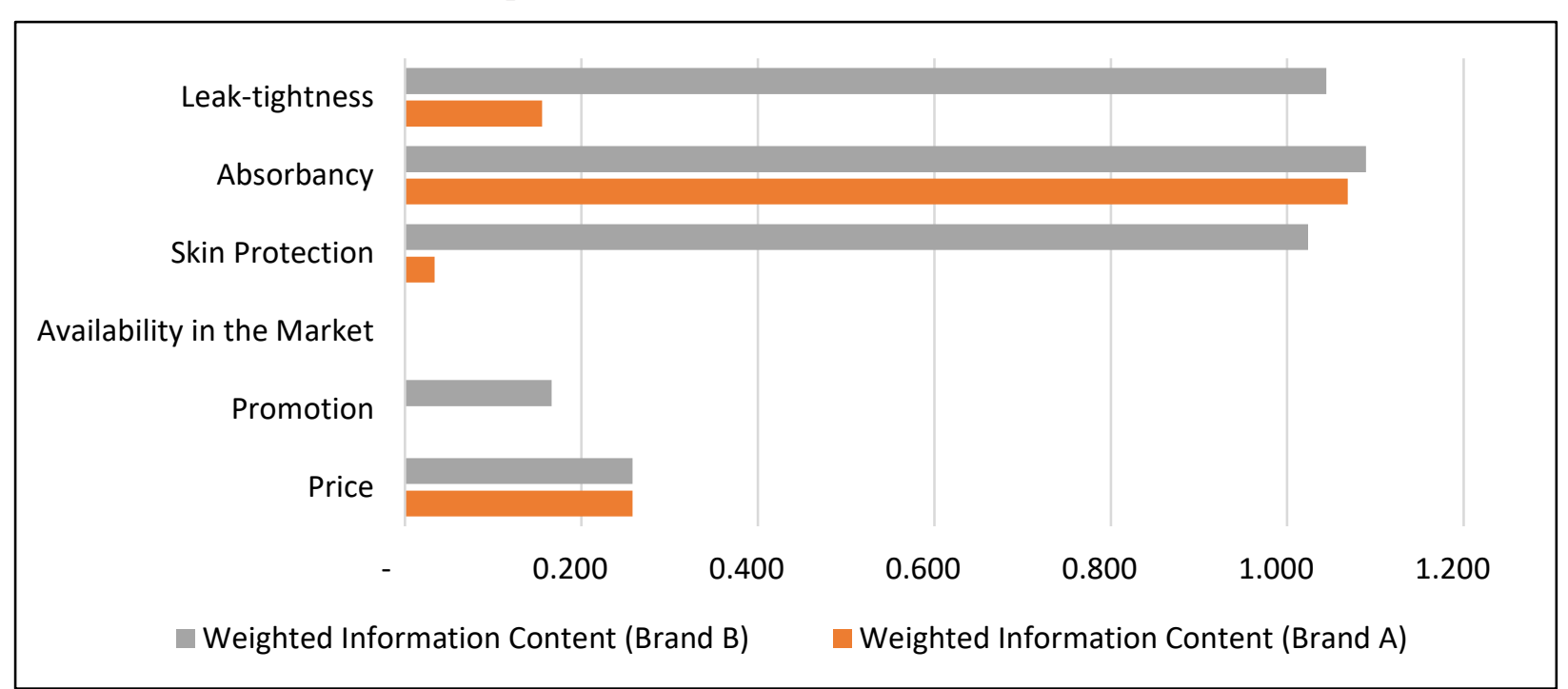

Figure 5: Weighted information contents

For some criterias, there is a situation of equal competancy for these two brands. The most important one is Price criteria. This is showing us, both brands have analyzed the market needs and paid enough attention to meet customer demands on most important selection criteria.

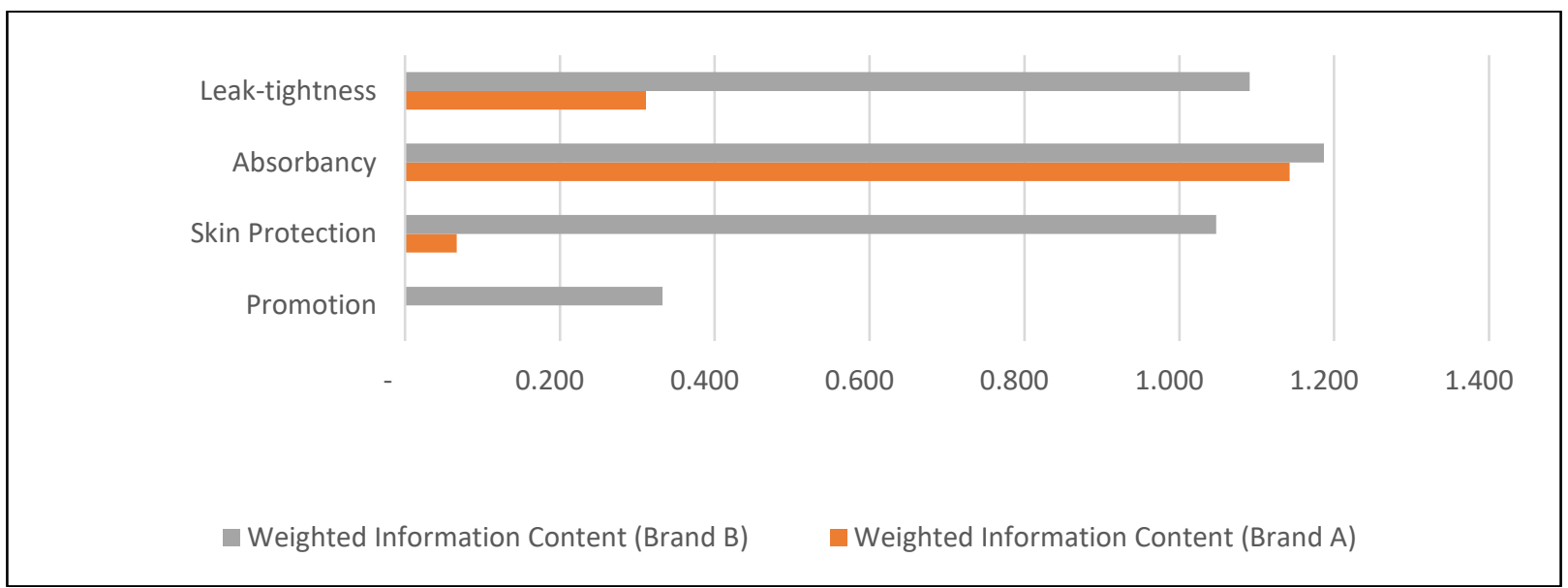

Figure 6: Weighted information contents with reduced criterias

Later than eliminating the criterias which has equal information content for both brands, model runs with recalculated priorities are as shown on Figure 6.

Except Skin Protection, the criteria which has the least Priority, for all other criterias it is seen that Brand B is not fullfilling customer requirements. Consequently, it can be said that Brand B must focus on those weak points during marketing and $R \& D$ activities.

Starting from this point, to be a subject of a further study, a new model can be built in order to decide which actions to take for reducing the cost and accordingly the price of the product. By reducing the price, information content will be minimized so this brand will have higher priority than the other competitor. 


\section{References}

[1] Saaty, T. L. (1986). Axiomatic foundation of the analytic hierarchy process, Management Science, 32(7), 841-855, https://doi.org/10.1287/mnsc.32.7.841.

[2] Saaty T. L. (1994). Fundamentals of decision making and priority theory with the analytic hierarchy process, RWS Publications, Pittsburg.

[3] Saaty T.L. (1999). Fundamentals of the analytic network process, ISHAP, Kobe JAPAN.

[4] Aragonés-Beltrán, P., García-Melón, M., \& Montesinos-Valera, J. (2017). How to assess stakeholders' influence in project management? A proposal based on the analytic network process, International Journal of Project Management, 35(3), 451-462, https://doi.org/10.1016/j.ijproman.2017.01.001.

[5] Gur, S., Bedir, N., \& Eren, T. (2017). Selection of marketing strategies with analytical network process and promethee method for medium sized business in food sector, Nevsehir Journal of Science and Technology, 6 (1), 79-92, DOI: 10.17100/nevbiltek.331412.

[6] Asadabadi, M. R. (2017). A customer based supplier selection process that combines quality function deployment, the analytic network process and a markov chain, European Journal of Operational Research, 263 (3), 1049-1062, https://doi.org/10.1016/j.ejor.2017.06.006.

[7] Ozcan, E. C., Unlusoy, S., \& Eren, T. (2017). Evaluation of the renewable energy investments in Turkey using anp and topsis methods, Selcuk University Journal of Engineering, Science and Technology, 5 (2), 204-219, DOI: 10.15317/Scitech.2017.82

[8] Martino, G., Fera, M., Iannone, R., \& Miranda, S. (2017). Supply chain risk assessment in the fashion retail industry: an analytic network process approach, International Journal of Applied Engineering Research, 12 (2), 140-154.

[9] Wan, S. P., Xu, G. L., \& Dong, J. Y. (2017). Supplier selection using anp and electre ii in interval 2-tuple linguistic environment, Information Sciences, 385, 19-38, DOI: 10.1016/j.ins.2016.12.032

[10] Zhang, J. (2016). Weighing and realizing the environmental, economic and social goals of tourism development using an Analytic network process-goal programming approach, Journal of Cleaner Production, 127, 262-273, https://doi.org/10.1016/j.jclepro.2016.03.131.

[11] Gok, A. C., \& Percin, S. (2016). Dematel-anp-vikor approach for assessing the e-service quality of electronic shopping (e-shopping) sites, Anadolu University Journal of Social Sciences, 16(1), 131144, DOI: 10.18037/ausbd.389223.

[12] Dincer, H., Hacioglu, U., \& Yuksel, S. (2016). Balanced scorecard-based performance assessment of turkish banking sector with analytic network process, International Journal of Decision Sciences \& Applications-IJDSA, 1 (1), 1-21.

[13] Hussain, M., Awasthi, A., \& Tiwari, M. K. (2016). Interpretive structural modeling-analytic network process integrated framework for evaluating sustainable supply chain management alternatives, Applied Mathematical Modelling, 40 (5-6), 2016, 3671-3687, DOI: 10.1016/j.apm.2015.09.018.

[14] Ocampo, L. A., \& Seva, R. R. (2016). Using analytic network process for evaluating mobile text entry methods, Applied Ergonomics, 52, 232-241, https://doi.org/10.1016/j.apergo.2015.07.022.

[15] Molinos-Senante, M., Gómez, T., Caballero, R., Hernández-Sancho, F., \& Sala-Garrido, R. (2015). Assessment of wastewater treatment alternatives for small communities: an analytic network process approach, Science of The Total Environment, 532, 676-687, https://doi.org/10.1016/j.scitotenv.2015.06.059.

[16] Suh, N.P. (1990). The principles of design, Oxford University Press, New York.

[17] Arcidiacono, G., Matt, D. T., \& Rauch, E. (2017). Axiomatic design of a framework for the comprehensive optimization of patient flows in hospitals, Journal of Healthcare Engineering, 2017, 1-9, https://doi.org/10.1155/2017/2309265.

[18] Gungor, F. (2017). Selection of seal material by axiomatic design method, El-Cezeri Journal of Science and Engineering, 4 (1), 1-10, DOI: 10.31202/ecjse.289632. 
[19] Babur, F., Cevikcan, E., \& Durmusoglu, M. B. (2016). Axiomatic design for lean-oriented occupational health and safety systems: an application in shipbuilding industry, Computers \& Industrial Engineering, 100, 88-109, https://doi.org/10.1016/j.cie.2016.08.007.

[20] Salonitis, K. (2016). Design for additive manufacturing based on the axiomatic design method, The International Journal of Advanced Manufacturing Technology, 87 (1-4), 989-996, https://doi.org/10.1007/s00170-016-8540-5.

[21] Zaral1, F., \& Yazgan, H. R. (2016). Solution of logistics center selection problem using the axiomatic design method, World Academy of Science, Engineering and Technology International Journal of Computer and Information Engineering, 10 (3), 489-495.

[22] Oliveira, L. E. S., \& Álvares, A. J. (2016). Axiomatic design applied to the development of a system for monitoring and teleoperation of a cnc machine through the internet, Procedia Cirp, 53, 198-205, https://doi.org/10.1016/j.procir.2016.06.099.

[23] Liu, A., \& Li, T. M. (2016). Develop habit-forming products based on the axiomatic design theory, Procedia CIRP, 53, 119-124, https://doi.org/10.1016/j.procir.2016.07.035.

[24] Arcidiacono, G., Yang, K., Trewn, J., \& Bucciarelli, L. (2016). Application of axiomatic design for project-based learning methodology, Procedia CIRP, 53, 166-172, https://doi.org/10.1016/j.procir.2016.08.003.

[25] Saaty T. L. (1996). Decision making with dependence and feedback: the analytic network process, RWS Publications, USA.

[26] Saaty T. L., \& Vargas L. G. (2006). Decision making with the analytic network process economic, political, social and technological applications with benefits, opportunities, costs and risks, Springer's International Series / Operational Research \& Management Science, Pittsburgh USA.

[27] Karabacak G. (2012). Munition selection with analytic hierarchy process and analytic network process, Master Thesis, Atatürk University, Graduate School of Natural and Applied Sciences, Erzurum.

[28] Alkan S. (2009). A supplier selection problem with analytic network process, axiomatic design and weighted axiomatic design approaches, Master Thesis, Kocaeli University, Graduate School of Natural and Applied Sciences, Kocaeli.

[29] Suh, N.P. (1998). Axiomatic design theory for systems, Research in Engineering Design, 10 (4), 189-209, https://doi.org/10.1007/s001639870001.

\footnotetext{
*Corresponding author.

E-mail address: aalkan@ kocaeli.edu.tr
} 